\title{
Effect of Polystyrene on Quenching Rate of Benzil Phosphorescence by Anthracene in Fluid Solution
}

\author{
Kazuyuki Horie and Itaru Mita \\ Institute of Space and Aeronautical Science, University of Tokyo, \\ Komaba, Meguro-ku, Tokyo 153, Japan. \\ (Received September 12, 1975) \\ KEY WORDS Fast Reaction / Benzil / Phosphorescence / Poly- \\ styrene / Quenching Rate / Diffusion Coefficient / Polymer Effect /
}

The dynamic flexibility of polymer chains in solution has received increasing interest in recent years. The fluorescence depolarization method has been utilized for the investigation of local motion of polymer segments. ${ }^{1}$ The use of fluorescence quenching was suggested as a molecular probe for studies of fast intra- and inter-macromolecular collisions reflecting the conformation changes of a polymer chain as a whole, but the short life times of the usual fluorescent compounds $\left(10^{-7}-10^{-9} \mathrm{sec}\right)^{2}$ in comparison with the relaxation times $^{3}$ for collision and overlapping of polymer molecules prevent its successful application in getting much insight into the molecular motions of the polymer chain. Some aromatic and aliphatic $\alpha$-diketones have been reported to phosphoresce even in fluid solution at room temperature. ${ }^{4-6}$ Their mean life times of phosphorescence lie in the range of $10^{-4}$ $10^{-5} \mathrm{sec}$ at $25^{\circ} \mathrm{C} .^{5}$ Thus, the use of benzil as a molecular probe gives a possibility of measuring directly the rates of fast intra- and inter-macromolecular collisions in solution.

The present communication is concerened with the measurement of quenching rates of benzil phosphorescence by anthracene at $25^{\circ} \mathrm{C}$ in benzene in the presence of various concentrations of polystyrene. It has revealed not only the effect of the polystyrene chain on benzil phosphorescence, but also some new aspects of the diffusion behavior of small molecules in polymer solution.

The luminescence spectra were measured with a Hitachi MPF-2A Fluorescence Spectrophotometer for solutions degassed and sealed under high vacuum. The polystyrenes were standard ones with narrow molecular weight distributions from Pressure Chemical Co. Typical spectra of benzil in benzene at $25^{\circ} \mathrm{C}$ are shown in Figure 1. As the fluorescence intensity at $505 \mathrm{~nm}$ changed with the concentration of neither anthracene nor polystyrene, it served as an internal standard for the calculation of the phosphorescence intensity at $560 \mathrm{~nm}$. Under photostationary conditions, the phosphorescence intensity of benzil, $I$, can be related to the concentrations of polystyrene $[\mathrm{P}]$ and anthrance $[\mathrm{A}]$ by

$$
I_{0} / I=1+k_{\mathrm{d}} \tau_{0}[\mathrm{P}]+k_{\mathrm{q}} \tau_{0}[\mathrm{~A}]
$$

where $I_{0}$ is $I$ in the absence of anthracene and polystyrene, $\tau_{0}$ is the mean life time of triplet

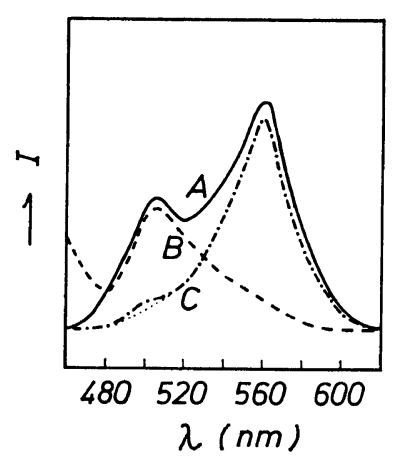

Figure 1. Luminescence spectra of benzil in benzene solution: (A) Unsensitized luminescence, benzil $1 \times 10^{-3} \mathrm{~mol} / l$ excited at $410 \mathrm{~nm}$; (B) fluorescence, benzil $1 \times 10^{-3} \mathrm{~mol} / l$ and anthracence $5 \times$ $10^{-5} \mathrm{~mol} / l$ excited at $410 \mathrm{~nm}$; (C) sensitized phosphoresence, 2-acetonaphthone $1 \times 10^{-2} \mathrm{~mol} / \mathrm{l}$ and benzil $1 \times 10^{-3} \mathrm{~mol} / l$ excited at $340 \mathrm{~nm}$. 
state benzil without anthracene and polystyrene, and $k_{\mathrm{d}}$ and $k_{\mathrm{q}}$ are respectively its rate constants for deactivation by polystyrene and for quenching by anthracene. Decay curves of phosphorescence intensity at $560 \mathrm{~nm}$ after an excitation with a $2-\mu$ sec flash lamp were also observed with a memory-type oscilloscope in some cases. The observed life time $\tau$ is related to $[\mathrm{P}]$ and $[\mathrm{A}]$ by

$$
1 / \tau=1 / \tau_{0}+k_{\mathrm{d}}[\mathrm{P}]+k_{\mathrm{q}}[\mathrm{A}]
$$

The value of $\tau_{0}$ was obtained to be $(6.8 \pm 0.4) \times$ $10^{-5} \mathrm{sec}$ in benzene at $25^{\circ} \mathrm{C}$ with the flash method: this agreed well with the literature value, $7.1 \times$ $10^{-5}$ sec. $^{5}$

The deactivation of triplet state benzil by polystyrene in the absence of anthracene is illustrated in Figure 2. Plots of $I_{0} / I$ versus polystyrene concentration $[\mathrm{P}]$ give a single straight line for polystyrene of various molecular weights. By assuming the independence of $\tau_{0}$ from the change in local viscosity around benzil by the addition of polystyrene, the deactivation rate constant by polystyrene, $k_{\mathrm{d}}$ was determined from eq 1 to be $1.9 \times 10^{3} \mathrm{l} / \mathrm{basemol} \mathrm{sec}$ by use of the slope and $\tau_{0}$ value.

Typical quenching plots of triplet benzil by anthracene in the absence and presence of polystyrene are shown in Figure 3. The quenching rate constant by anthracene, $k_{\mathrm{q}}$, for each polystyrene concentration was calculated from the slope and $\tau_{0}$ vaule.

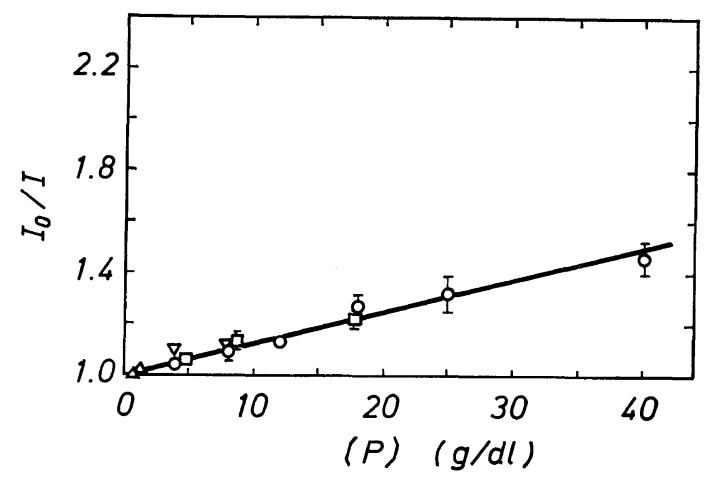

Figure 2. Effect of polystyrene concentration [P] on phosphorescence intensity of benzil in the absence of anthracene. Molecular weight of polystyrene: $\bigcirc, 2.2 \times 10^{3} ; \square, 3.7 \times 10^{4} ; \nabla, 2.0 \times 10^{5}$; $\triangle, 3.2 \times 10^{6}$.

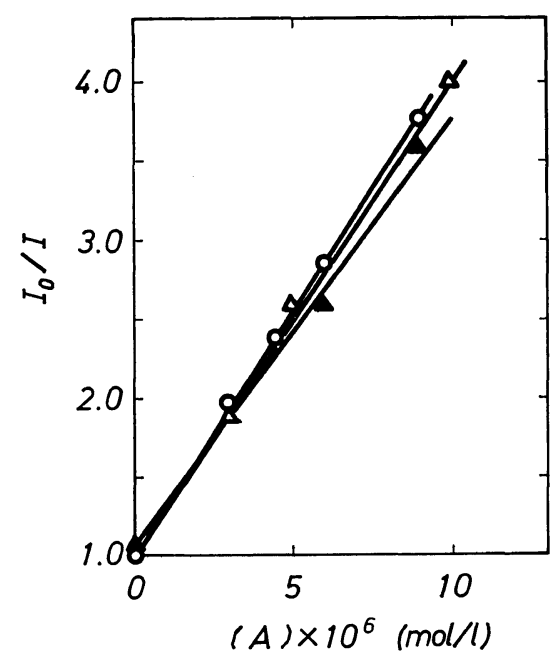

Figure 3. Quenching plots of benzil phosphorescence by anthracene. Benzil concentration $1.0 \times$ $10^{-3} \mathrm{~mol} / l: \quad \bigcirc,[\mathrm{P}]=0 ; \triangle,[\mathrm{P}]=0.5 \mathrm{~g} / \mathrm{d} l, M=3.2 \times$ $10^{6} ; \Delta,[\mathrm{P}]=1.0 \mathrm{~g} / \mathrm{d} l, M=3.2 \times 10^{6}$.

It is well-known that the rate of triplettriplet energy transfer is controlled by the diffusion process of the donor and acceptor, provided that the lowest triplet energy $E_{\mathrm{T}}$ of the former is higher than $E_{\mathrm{T}}$ of the latter by more than several $\mathrm{kcal} / \mathrm{mol}$. This condition holds for the present case, since the values of $E_{\mathrm{T}}$ are 53.4 and $42.0 \mathrm{kcal} / \mathrm{mol}$ for benzil and anthracene, respectively. ${ }^{2}$ The bimolecular rate constant for a diffusion-controlled reaction, $k_{\mathrm{D}}$, is given according to Debye ${ }^{7}$ by

$$
k_{\mathrm{D}}=4 \pi R D=8 k_{\mathrm{B}} T / 3 \eta
$$

where $R$ is the sum of hydrodynamic radii of the reacting species, $D$ the sum of their diffusion coefficents, $\eta$ the viscosity of the medium, $k_{\mathrm{B}}$ Boltzmann's constant, $T$ temperature. Equation 3 has been derived for encounters between two spherical particles with uniform reactivity and the same size. The value of $k_{\mathrm{q} 0}=4.6 \times$ $10^{9} \mathrm{l} / \mathrm{mol} \mathrm{sec}$, which has been obtained in the solution without polystyrene, is small compared with the calculated value of $k_{\mathrm{D}}, 1.1 \times 10^{10} \mathrm{l} / \mathrm{mol} \mathrm{sec}$, from eq 3. The difference would be attributed to a steric factor $^{8}$ arising from the specified reactive locus on the surface of triplet benzil. ${ }^{9}$

The quenching rate constants $k_{\mathrm{q}}$ in the presence of polystyrene are plotted in Figure 4 against the solution viscosity $\eta_{\mathrm{s}}$, which has been 


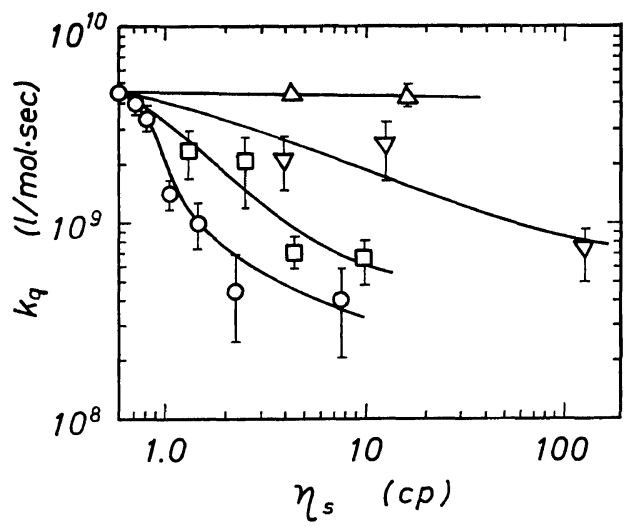

Figure 4. Quenching rate constant $k_{\mathrm{q}}$ of benzil phosphorescence by anthracene at $25^{\circ} \mathrm{C}$ versus solution viscosity $\eta_{\mathrm{s}}$. Molecular weight of polystyrene: $\bigcirc, 2.2 \times 10^{3} ; \square, 3.7 \times 10^{4} ; \nabla, 2.0 \times 10^{5} ; \triangle$, $3.2 \times 10^{6}$.

measured by using a Ubbelohde-type viscometer. According to eq 3, the data in Figure 4 also express the dependence of the sum of the diffusion coefficients of benzil and anthracene $D$ on $\eta_{\mathrm{s}}$. In the presence of polystyrene having molecular weight $M=3.2 \times 10^{6}, k_{\mathrm{q}}$ and therefore $D$ are almost independent of $\eta_{\mathrm{s}}$, irrespective of large increases in $\eta_{\mathrm{s}}$, by more than a factor of 30. The highest concentration $(1.0 \mathrm{~g} / \mathrm{d} l)$ studied for polystyrene of $M=3.2 \times 10^{6}$ is above the critical concentration for incipient overlap of the encompassed average spherical coil volume. ${ }^{10}$ This result indicates that the benzil and anthracene molecules penetrate almost freely through polymer coils, and that the local viscosity around the diffusive molecules is almost the same as the viscosity of the pure solvent in this case. The values of $k_{\mathrm{q}}$ and therefore $D$ at a fixed $\eta_{\mathrm{s}}$ decrease with decreasing $M$. This would be caused by the fact that with decreasing $M$ greater values of $[\mathrm{P}]$ should be needed to obtain solutions having the same value of $\eta_{\mathrm{s}}$. Thus, the solution viscosity $\eta_{\mathrm{s}}$ is quite different from the $\eta$ in eq 3 , which corresponds to the local viscosity around diffusive molecules. It is suggested that $D$ would be concerned, not with the macroscopic solution viscosity $\eta_{\mathrm{s}}$, but with the polystyrene concentration $[\mathrm{P}]$. A similar situation has been reported for the cage reaction of tert-butoxy radicals in polystyrene-benzene solution. ${ }^{11}$

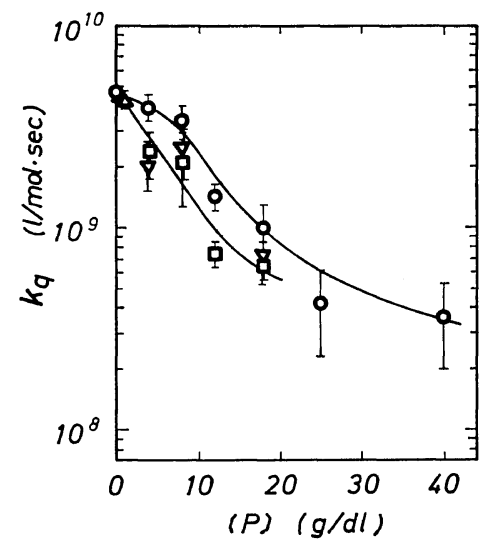

Figure 5. Dependence of quenching rate constant $k_{\mathrm{q}}$ on polystyrene concentration [P]. Molecular weight of polystyrene: $\bigcirc, 2.2 \times 10^{3} ; \square, 3.7 \times 10^{4}$; $\nabla, 2.0 \times 10^{5} ; \triangle, 3.2 \times 10^{6}$.

The dependence of $k_{\mathrm{q}}$ on [P] is shown in Figure 5. These data also show the dependence of $D$ on [P]. In a solution of polystyrene of $M=2,200, \quad k_{\mathrm{q}}$ decreases markedly at $[\mathrm{P}]=8$ $12 \mathrm{~g} / \mathrm{d} l$ and becomes about ten times smaller than $k_{\mathrm{q} 0}$ at $[\mathrm{P}]=40 \mathrm{~g} / \mathrm{d} l$. With polystyrene of $M=37,000$, the initial decrease in $k_{\mathrm{q}}$ occurs at $[\mathrm{P}] \leqq 4.0 \mathrm{~g} / \mathrm{d} l$. A further increase in molecular weight seems to result in little change in the dependence of $k_{\mathrm{q}}$ on [P]. In this connection it has been observed by using the NMR spin-echo technique that at a fixed [P] the self-diffusion coefficient of benzene in polystyrene-benzene solution is independent of molecular weight in the region $M>10^{4} .{ }^{12}$

The flexible chain of a macromolecule has been suggested to act mainly as an obstacle for the translational motion of small molecules in polymer solution. ${ }^{13}$ The diffusivity of small molecules is hardly affected by the change in molecular weight of polymer at a certain [P], but is influenced by the volume fraction of polymer segments in a solution.

The dimension of a small molecule also affects its diffusivity in polymer solution. The steep decrease in $D$ at $[\mathrm{P}]=4-12 \mathrm{~g} / \mathrm{d} l$ in the present case (Figure 5) is contrasted with a gentle decrease in $D$ with increasing $[\mathrm{P}]$ for the selfdiffusion of benzene in a polystyrene-benzene solution. ${ }^{12}$ These concentrations correspond to the boundary region where the influences on 
the usual solution properties of overlapping between polymer coils and network formation by entanglements cannot be neglected. It seems more difficult for a larger molecule to penetrate through such a polymer network, and it would be consistent that $D$ for benzil and anthracene becomes smaller than that for benzene in this region of polymer concentration. The small decrease in $D$ for the case of $M=3.2 \times 10^{6}$ and $[\mathrm{P}]=1.0 \mathrm{~g} / \mathrm{d} l$, in spite of the occurrence of overlapping, can be attributed to the very low density of segments inside the polymer coil due to the very high molecular weight and the expansion of the polymer coil in good solvent.

In conclusion, polystyrene affects the quenching rate of benzil phosphorescence by anthracene in solution mainly as an obstacle for diffusion of the reactants. The influence of polystyrene on benzil phosphorescence has also been considered. The phosphorescene quenching in solution serves as an effective probe for diffusion behavior in a polymer solution. Application of this technique to diffusion-controlled macromolecular reactions is left to further investigation.

Acknowledgment. The authors wish to express their gratitude to Professor K. Tokumaru and the members of his group in Tokyo University for the use of the fluoresence spectrophotometer.

\section{REFERENCES}

1. Y. Nishijima, J. Polym. Sci, Part C, No. 31, 353 (1970).

2. S. L. Murov, "Handbook of Photochemistry," Marcel Dekker Inc., New York, N.Y., 1973.

3. K. Horie, I, Mita, and H. Kambe, Polymer J., 4, 341 (1973).

4. H. L. J. Bäckström and K. Sandros, Acta Chem. Scand., 12, 823 (1958).

5. H. L. J. Bäckström and K. Sandros, ibid., 14, 48 (1960).

6. H. H. Richtol and F. H. Klappmeier, J. Chem. Phys., 44, 1519 (1966).

7. P. Debye, Trans. Electrochem. Soc., 82, 265 (1942).

8. K. Šolc and W. H. Stockmayer, J. Chem. Phys., 54, 2981 (1971).

9. D. J. Morantz and A. J. C. Wright, ibid., 54, 692 (1971).

10. R. Simha and J. L. Zakin, ibid., 33, 1791 (1960).

11. E. Niki and Y. Kamiya, J. Amer. Chem. Soc., 97, 2129 (1974).

12. K. Goffloo and R. Kosfeld, Angew. Makromol. Chem., 37, 105 (1974).

13. M. Nakagawa, S. Ishida, and K. Kaneko, Kobunshi Kagaku (Chem. High Polymers), 29, 661 (1972). 